\title{
Análise bibliométrica do uso de células-tronco em pesquisas odontológicas
}

\author{
Bibliometric analysis of the use of stem cells in odontological research \\ Análisis bibliométrico del uso de células madre en la investigación odontológica \\ Jéssica Gomes Alcoforado de MELO ${ }^{1}$ \\ Diego Moura SOARES ${ }^{\mathbf{1}, 2}$ \\ ${ }^{1}$ Professor do Curso de Odontologia da Faculdade de Integração do Sertão (FIS), 56909-205 Serra Talhada-PE, Brasil \\ ${ }_{2}^{2}$ Professor do Curso de Odontologia da Faculdade Pernambucana de Saúde (FPS), 51150-000 Recife-PE, Brasil
}

\begin{abstract}
Resumo
As pesquisas com células-tronco, seja de origem dental ou não, vêm crescendo na área da odontologia nos últimos anos em decorrência das possibilidades terapêuticas que a utilização desse tipo celular oferece. Este estudo visa demonstrar um panorama brasileiro das pesquisas com células-tronco realizadas no país por pesquisadores da área da odontologia nos anos de 2014 até 2018 , com base nos anais de trabalhos apresentados nas Reuniões Anuais da Sociedade Brasileira de Pesquisa Odontológica (SBPqO). Foi analisado aspectos como tipo de instituição, se as pesquisas foram financiadas e qual a agencia de fomento, tipo de estudo, estado e região que desenvolveu a pesquisa, tipo de célula e fonte da célula-tronco utilizada. Foram analisados um total de 15,214 resumos, deste total 96 estudos foram incluídos por se enquadrarem com os critérios de inclusão. A região Sudeste foi responsável por 65,7\% dessa produção. As pesquisas realizadas nas instituições estaduais representaram $42,7 \%$ da produção nacional e 59,4\% dos trabalhos foram financiados. As células-tronco humanas foram o tipo mais utiilizado, especialmente as originadas da polpa dentária (25\%). Conclui-se que há uma escassez da produção científica voltada para as células-tronco na odontologia, bem como a necessidade de descentralização dessa produção nas demais regiões brasileiras.
\end{abstract}

Descritores: Células-Tronco; Odontologia; Pesquisa em Odontologia.

\section{Abstract}

Research with stem cells, whether dental or not, has been growing in the area of dentistry in recent years due to the therapeutic possibilities that the use of this type of cell offers. This study aims to demonstrate a Brazilian research overview of stem cell conducted in the country by dental researchers from 2014 to 2018, based on the annals of papers presented at the Annual Meetings of the Brazilian Society for Dental Research (SBPqO). Aspects such as the type of institution, whether the research was funded and the funding agency, type of study, state and region that conducted the research, type of cell and source of the stem cell used were analyzed. A total of 15,214 abstracts were analyzed, of which 96 studies were included because they met the inclusion criteria. The Southeast region accounted for $65.7 \%$ of this production. Research conducted at state institutions accounted for $42.7 \%$ of national production and $59.4 \%$ of works were funded. Human stem cells were the most used type, especially those originating from dental pulp (25\%). It is concluded that there is a shortage of scientific production focused on stem cells in dentistry, as well as the need for decentralization of this production in other Brazilian regions.

Descriptors: Stem Cells; Dentistry; Dental Research.

\section{Resumen}

La investigación con células madre, ya sea dental o no, ha estado creciendo en el área de la odontología en los últimos años debido a las posibilidades terapéuticas que ofrece el uso de este tipo de células. Este estudio tiene como objetivo demostrar una visión general brasileña de la investigación con células madre realizada en el país por investigadores dentales de 2014 a 2018 , basada en los anales de documentos presentados en las Reuniones Anuales de la Sociedad Brasileña de Investigación Dental (SBPqO). Se analizaron aspectos como el tipo de institución, si la investigación fue financiada y la agencia de financiación, tipo de estudio, estado y región que realizó la investigación, tipo de célula y fuente de la célula madre utilizada. Se analizaron un total de 15.214 resúmenes, de los cuales se incluyeron 96 estudios porque cumplían los criterios de inclusión. La región sudeste representó el $65.7 \%$ de esta producción. Las investigaciones realizadas en instituciones estatales representaron el $42.7 \%$ de la producción nacional y el 59.4\% de las obras fueron financiadas. Las células madre humanas fueron el tipo más utilizado, especialmente las que se originan en la pulpa dental $(25 \%)$. Se concluye que hay una escasez de producción científica centrada en células madre en odontología, así como la necesidad de descentralizar esta producción en otras regiones brasileñas.

Descriptores: Células Madre; Odontología; Investigación Dental.

\section{INTRODUÇÃO}

As células-tronco são comumente definidas como células indiferenciadas que, quando induzidas corretamente, apresentam grande capacidade de autorenovação e de diferenciação em tipos celulares especializados $^{1,2}$. Baseado em sua capacidade de originar um ou mais tipos celulares especializados, são classificadas em diferentes níveis de potencialidade, incluindo a totipotência do zigoto, a pluripotência de uma célula-tronco embrionária, a multipotência de uma célula-tronco do tecido adulto e a unipotência de tipos celulares específicos ${ }^{3}$.

Diversos tecidos e órgãos são considerados como fontes de células-tronco adultas, tais como: medula óssea ${ }^{4}$, tecido adiposo ${ }^{5}$, cordão umbilical, sangue, córnea, retina e pâncreas ${ }^{7}$. Há alguns anos, inúmeros estudos têm isolado células-tronco derivadas dos tecidos orais, dentre os quais podemos citar a polpa de dentes permanentes ${ }^{1}$, a polpa de dentes decíduos ${ }^{8}$ e o ligamento periodontal ${ }^{9}$.

As pesquisas com células-tronco sejam de origem dental ou não, vêm crescendo na área da odontologia nos últimos anos em decorrência das possibilidades terapêuticas que a utilização desse tipo celular oferece. Estudos avaliando a sua capacidade de diferenciação em outros tipos celulares ${ }^{10}$, artigos verificando a sua proliferação ${ }^{11,12} \mathrm{e}$ meios de criopreservação ${ }^{13}$. Porém, pouco se sabe com relação a fatores como instituições que realizam pesquisas com células-tronco, quais os estados e regiões do Brasil que elas estão concentradas e se esses estudos estão sendo financiados, visto que são pesquisas de alto custo.

Dessa forma, este artigo visa apresentar um panorama brasileiro das pesquisas realizada no país por pesquisadores da área da Odontologia, nos anos de 2014 até 2018. Esta pesquisa analisou aspectos como tipo de instituição, se as pesquisas foram financiadas e qual a agencia de fomento, tipo de estudo, estado e região que desenvolveu a pesquisa, tipo de célula e fonte da célula-tronco utilizada. 


\section{MATERIAL E MÉTODO}

Este trabalho, trata-se de um estudo bibliométrico, tendo como base os anais dos trabalhos apresentados nas Reuniões Anuais da Sociedade Brasileira de Pesquisa Odontológica (SBPqO) de 2014 até o ano de 2018, disponíveis online no site da referida sociedade (www.sbpqo.org.br/resumos/index.asp). Foram analisados os resumos que tinham relação com qualquer tema ligado a células-tronco. De acordo com Maciel et al. ${ }^{14}$ as reuniões anuais da $\mathrm{SBPqO}$ é o maior encontro de cunho científico da odontologia brasileira, por isso a opção de se realizar esta pesquisa nos anais do $\mathrm{SBPqO}$, podendo obter material suficiente para criar um panorâma do que vem sendo desenvolvido cientificamente no Brasil por profissionais da Odontologia a cerca de diversos temas.

Os dados foram coletados nos anais (resumos dos trabalhos aceitos para apresentação) das Reuniões Anuais da SBPqO, realizada entre os anos de 2014 à 2018, na cidade de Campinas ou Águas de lindóia, a depender do ano, ambas do estado de São Paulo. Os anais são disponibilizados publicamente, para toda a comunidade científica, logo após a conclusão das reuniões. A extração de dados foi realizada no período de janeiro a março de 2019, todos os resumos foram examinados por dois revisores e aqueles que possuíam alguma conexão com o tema foram incluídos no estudo.

Para pesquisa dos resumos utilizou-se a seguinte estratégia: localização dos termos "Célulatronco" e "Stem-cell", tanto no singular como no plural, utilizando a ferramenta de busca, garantindo que todas as e permitiu que todos os trabalhos, publicados em inglês ou português, pudessem ser analizados. Todas as categorias dos anais foram avaliadas e todos os dados utilizados neste estudo são de acesso público.

As etapas descritas a seguir foram realizadas, separadamente, por dois pesquisadores devidamente calibrados. Foram incluídos para análise final todos os trabalhos que atenderam os seguintes critérios de inclusão: resumos que claramente abordaram a utilização de células-tronco em qualquer tipo de pesquisa / área, originados de pesquisas desenvolvidas por uma instituição de ensino brasileira e publicados nos anais de 2014 a 2018, na língua portuguesa ou inglesa. Os resumos que suscitaram dúvidas aos avaliadores durante a fase de triagem foram mantidos para uma avaliação mais detalhada, através de uma reunião de consenso entre os dois examinadores.

Para a coleta de dados, após a seleção dos resumos, foi desenvolvida uma planilha própria no programa Excel (2013), versão Professional Plus, contendo informações relativas à instituição onde o trabalho foi desenvolvido, estado e região do país.
Foram levados em consideração ainda o tipo de instituição (Privada, Estadual, Federal ou Autarquia Municipal), a origem e fonte celular, se houve financiamento e a agência de fomento e o tipo de pesquisa realizada. Os dados coletados foram baseados em estudos publicados anteriormente que utilizaram metodologias semelhantes ${ }^{14-16}$. A análise estatística foi realizada a partir de estatística descritiva (distribuição de frequência) e analítica a partir do teste de qui-quadrado, sendo todas as análises realizadas no programa SPSS na versão 16 e apresentada na forma de porcentagem e valor absoluto.

\section{RESULTADOS}

Foram analisados 15,214 resumos publicados nos anais das reuniões de 2014 até 2018, deste total 96 estudos foram incluídos por se enquadrarem com os critérios de inclusão desta pesquisa, sendo que deste total, $20(20,8 \%)$ resumos foram publicados em 2014, 28 (29,2\%) em 2015, 19 (19,8\%) em 2016, 17 $(17,7 \%)$ no ano de 2017 e $12(12,5 \%)$ resumos encontrados nos anais de 2018. Com relação à distribuição dos resumos por região do país, o Sudeste apresentou um maior número de publicações, mais detalhes podem ser verificados na Tabela 1 .

Tabela 1. Distribuição dos trabalhos de acordo com a região e estado brasileiro

\begin{tabular}{|c|c|c|c|}
\hline Região & Estado & $\begin{array}{c}\text { Frequência } \\
\text { (n)* }\end{array}$ & $\% *$ \\
\hline \multirow[t]{2}{*}{ Centro-Oeste } & Goiás & 5 & \\
\hline & Mato Grosso & 1 & \\
\hline \multicolumn{2}{|r|}{ Total da Região } & 6 & 6,25 \\
\hline \multirow[t]{6}{*}{ Nordeste } & Ceará & 1 & \\
\hline & Paraíba & 1 & \\
\hline & Pernambuco & 2 & \\
\hline & Piauí & 1 & \\
\hline & Rio Grande do Norte & 6 & \\
\hline & Total da Região & 11 & 11,45 \\
\hline Norte & Pará & 3 & \\
\hline \multicolumn{2}{|r|}{ Total da Região } & 3 & 3,14 \\
\hline \multirow[t]{4}{*}{ Sudeste } & Minas Gerais & 11 & \\
\hline & Rio de Janeiro & 2 & \\
\hline & São Paulo & 50 & \\
\hline & Total da Região & 62 & 64,58 \\
\hline \multirow[t]{4}{*}{ Sul } & Paraná & 5 & \\
\hline & Rio Grande do Sul & 3 & \\
\hline & Santa Catarina & 6 & \\
\hline & Total da Região & 14 & 14,58 \\
\hline \multicolumn{2}{|l|}{ TOTAL } & 96 & 100 \\
\hline
\end{tabular}

A Tabela 2 demonstra a distribuição dos estudos incluídos de acordo com o tipo de instituição, sendo as instituições estaduais as que mais produziram acerca do tema. De acordo com o tipo de pesquisa os trabalhos foram distribuição em estudos experimentais in vitro, sendo os mais frequentes, com 52 resumos $(54,2 \%)$, experimentais in vivo com 33 $(34,4 \%)$ dos trabalhos, estudos clínicos com $6(6,2 \%)$ artigos, $4(4,2 \%)$ dos resumos publicados tratavam-se de revisões sistemáticas e 1 dos trabalho (1\%) foi classificado como observacional do tipo transversal. Dos 96 resumos incluídos, 57 resumos receberam algum tipo de financiamento, o que corresponde a um total de 59,4\%. A distribuição dos trabalhos de acordo com o recebimento de fomento (agência 
financiadora) e a região do país encontra-se na Tabela 3.

Tabela 2. Distribuição dos trabalhos de acordo com o tipo de instituição (federal, estadual e privada) e região do país

\begin{tabular}{|c|c|c|c|}
\hline Instituição & Região & $\begin{array}{c}\text { Frequência } \\
\text { (n)* }\end{array}$ & \%* \\
\hline \multirow{5}{*}{ Federal } & Nordeste & 9 & \\
\hline & Norte & 2 & \\
\hline & Sudeste & 12 & \\
\hline & Sul & 11 & \\
\hline & Centro-Oeste & 6 & \\
\hline \multirow{3}{*}{ Estadual } & Total & 40 & 41,7 \\
\hline & Nordeste & 3 & \\
\hline & Sudeste & 38 & \\
\hline \multirow{3}{*}{ Privada } & Total & 41 & 42,7 \\
\hline & Sudeste & 13 & \\
\hline & Sul & 3 & \\
\hline \multicolumn{2}{|r|}{ Total } & 16 & 15,6 \\
\hline \multicolumn{2}{|l|}{ TOTAL } & 97 & 100 \\
\hline
\end{tabular}

Tabela 3. Distribuição dos trabalhos de acordo com o recebimento de fomento (agência financiadora) e a região do país

\begin{tabular}{|c|c|c|c|}
\hline Agência & Região & $\begin{array}{c}\text { Frequência } \\
\text { (n)* }\end{array}$ & $\%^{*}$ \\
\hline Sem fomento & & 39 & 40,6 \\
\hline \multirow{4}{*}{ CNPq } & Centro-Oeste & 1 & \\
\hline & Nordeste & 1 & \\
\hline & Sudeste & 6 & \\
\hline & Sul & 1 & \\
\hline \multicolumn{2}{|r|}{ Total } & 9 & 9,3 \\
\hline \multirow{3}{*}{ FAPs } & Nordeste & 1 & \\
\hline & Sudeste & 30 & \\
\hline & Sul & 1 & \\
\hline \multicolumn{2}{|r|}{ Total } & 32 & 33,3 \\
\hline \multirow{5}{*}{ CAPES } & Centro-Oeste & 1 & \\
\hline & Sudeste & 9 & \\
\hline & Sul & 1 & \\
\hline & Nordeste & 2 & \\
\hline & Norte & 1 & \\
\hline \multicolumn{2}{|r|}{ Total } & 13 & 13,5 \\
\hline CNPq+ FAPs & Sul & 1 & \\
\hline \multicolumn{2}{|r|}{ Total } & 1 & 1,1 \\
\hline \multirow{2}{*}{ CAPES + FAPs } & Norte & 1 & \\
\hline & Sudeste & 1 & \\
\hline \multicolumn{2}{|r|}{ Total } & 2 & 2,1 \\
\hline TOTAL & & 96 & 100 \\
\hline
\end{tabular}

Dentre os 96 resumos incluídos no estudo, 68 $(70,8 \%)$ utilizaram células humanas e $28(29,2 \%)$ células provenientes de animais. Os ratos foram a espécie animal mais utilizada (19 estudos), seguidos por coelhos e porcos com 3 estudos cada. Apenas 1 dos artigos utilizou células de camundongos, 7 não informaram a fonte células e 1 outro, por se tratar de uma revisão sistemática, utilizou células animais sem especificar a espécie no resumo. As fontes das células-tronco utilizadas nos estudos podem ser verificadas na Tabela 4.

Tabela 4. Distribuição dos trabalhos de acordo com a fonte da célulastronco.

\begin{tabular}{lcc}
\hline Fonte & $\begin{array}{c}\text { Frequência } \\
\text { (n) }\end{array}$ & $\mathbf{\%}$ \\
\hline Medula Óssea & 19 & 19,8 \\
\hline Cordão Umbilical & 1 & 1,0 \\
\hline Tecido Adiposo & 2 & 2,1 \\
\hline Embrionária & 1 & 1,0 \\
\hline Papila Apical & 5 & 5,2 \\
\hline Folículo Dental & 2 & 2,1 \\
\hline Polpa Dentária & 24 & 25,0 \\
\hline Polpa de Dente Decíduo & 12 & 12,5 \\
\hline Papila e Polpa dental & 1 & 1,0 \\
\hline Polpa Dental e Ligamento Periodontal & 2 & 2,1 \\
\hline Medula Óssea e tecido Adiposo & 4 & 4,2 \\
\hline Tumorais/Neoplásicas & 14 & 14,6 \\
\hline Não especificou a fonte & 7 & 7,3 \\
\hline Várias fontes dentais* & 2 & 2,1 \\
\hline TOTAL & $\mathbf{9 6}$ & $\mathbf{1 0 0}$ \\
\hline *Trata-se de duas revisões sistemáticas que analisou todas as fontes de origem dental
\end{tabular}

\section{DISCUSSÃO}

As pesquisas com células-tronco são de grande importância para a busca de novas terapias para as mais diversas doenças. Embora conhecimento das possibilidades terapeuticas que estas células oferecem, constatou-se neste estudo que a o número de pesquisas odontológicas utilizado essas células é muito baixa. Pode-se observar que ainda houve uma diminuição dessa quantidade de estudos a partir do ano de 2015.

Como já visto em outros estudos de análise bibliométrica $^{14,17,18}$, o Sudeste foi o responsável por grande parte da produção analisada, sendo o estado de São Paulo o maior produtor desta região. Assim como, as instituições responsáveis por pesquisas com células-tronco foram desta mesma região, em especial, as instituições estaduais $(39,6 \%)$.

A pesquisa científica nas universidades de São Paulo é mais bem explorada do que em outras regiões ${ }^{18}$, especialmente por nesta região estarem localizadas os centros referências em pesquisas odontológicas $^{19}$. Os grandes centros, situados no eixo Sudeste, já apresentam resultados expressivos nas pesquisas sobre células-tronco ${ }^{20}$.

Assim como mencionado por Primo et al. ${ }^{21}$, o estudo experimental in vitro constituiu o desenho mais utilizado nas pesquisas odontológicas apresentadas no $\mathrm{SBPqO}$, seguido dos estudos in vivo.

Mais da metade dos estudos $(59,4 \%)$ receberam financiamento, o que está de acordo com o apoio e investimento do Ministério da Saúde em parceria com o Conselho Nacional de Desenvolvimento Científico e Tecnológico (CNPq) desde o ano de 2005 para com os estudos em terapia celular na medicina e odontologia ${ }^{22}$. Porém, em relação as pesquisas odontológicas com célulastronco, foi visto que as FAPs foram as responsáveis pela maior parte do financiamento, seguida da CAPES e do CNPq.

As células-tronco humanas se constituíram como a principal fonte de células para as pesquisas odontológicas, este fato foi confirmado por esse estudo, em especial quando se trata das célulastronco da polpa dentária (25\%), provavelmente por serem relativamentes facéis de se obter, exibirem uma forte capacidade de proliferação e por serem criopreservadas por mais tempo ${ }^{23}$, seguidas das células-tronco da medula óssea $(19,8 \%)$ e célulastronco tumorais/neoplásicas $(14,6 \%)$.

Por serem uma poderosa ferramenta promissora nos estudos de diferenciação e terapia de doenças ${ }^{24}$, as células-tronco dentárias (células-tronco da polpa dentária do dente decíduo $(12,5 \%)$, célulastronco da papila apical $(5,2 \%)$ e células-tronco do folículo dental $(2,1 \%))$ foram bastante utilizadas nas pesquisas analisadas. 


\section{CONCLUSÃO}

Diante do exposto, conclui-se que as pesquisas com células-tronco precisam de um maior incentivo, especialmente, nas outras regiões do país, descentralizando o núcleo de pesquisa da região Sudeste. Assim como um maior estímulo para as instituições federais e privadas aumentarem as pesquisas com células-tronco, em especial, célulastronco de origem dentárias.

\section{REFERÊNCIAS}

1. Gronthos S, Mankani M, Brahim J, Robey PG, Shi S. Postnatal human dental pulp stem cells (DPSCs) in vitro and in vivo. Proc Natl Acad Sci USA.2000;97(25):13625-630.

2. Freshney IR, Stacey GN, Aurebach JM. Culture of human stem cells: culture of specialized cells. New York: Wisley-Liss; 2007.

3. Serakinci N, Keith WN. Therapeutic potential of adult stem cells. Eur J Cancer.2006;42(9):1243-46.

4. Bianco P, Riminucci M, Gronthos S, Robey PG. Bone marrow stromal stem cells: nature, biology, and potential applications. Stem Cells.. 2001;19(3):180-92.

5. Mvula B, Mathope T, Moore T, Abrahamse H. The effect of low-level laser irradiation on adult human adipose-derived stem cells. Lasers Med Sci. 2008;23(3):277-82.

6. Kern S, Eichler H, Stoeve J, Klüter H, Bieback K. Comparative analysis of mesenchymal stem cells from bone marrow, umbilical cord blood, or adipose tissue. Stem Cells. 2006; 24(5):1294-301.

7. Slack JM. Stem cell in epithelial tissue. Science. 2000; 287:1431-33.

8. Miura M, Gronthos S, Zhao M, Lu B, Fisher LW, Robey PG et al. SHED: stem cells from human exfoliated deciduous teeth. Proc Natl Acad Sci USA.2003; 100(10):5807-12.

9. Chen SC, Marino V, Gronthos S, Bartold PM. Location of putative stem cells in human periodontal ligament. J Periodontal Res. 2006; 41(6):547-53.

10.Nuti N, Corallo C, Chan BMF, Ferrari M, Gerami-Naini B. Multipotent differentiation of human dental pulp stem cells: a literature review. Stem Cell Rev. 2016;12(5):511-523.

11.Barboza CAG, Ginani F, Soares DM, Henrique ACG, Freitas RA. Low-level laser irradiation induces in vitro proliferation of mesenchymal stem cells. Einstein (São Paulo) 2014;12(1):75-81.

12. Soares DM, Ginani F, Henriques AG, Barboza CAG. Effects of laser therapy on the proliferation of human periodontal ligament stem cells. Lasers Med Sci. 2015;30(3):1171-74.

13. Ginani F, Soares DM, Rabêlo LM, Rocha HAO, Souza LB, Barboza CAG. Effect of a cryopreservation protocol on the proliferation of stem cells from human exfoliated deciduous teeth. Acta Odontol Scand. 2016;74(8):598-604.

14. Maciel MMSA, Silva KBN, Melo JGA, Soares DM. Metodologia ativa aplicada ao ensino odontológico: um panorama nacional a partir de um estudo bibliométrico. Arch Health Invest. 2019;8(2):74-78.

15.Melo NB, Fernandes Neto JA, Catão MHCV, Bento PM. Metodologia da Problematização e Aprendizagem Baseada em Problemas na Odontologia: análise bibliométrica dos trabalhos apresentados nas Reuniões da SBPqO. Revista da ABENO 2017;17(2):60-7.

16.Xavier AFC, Silva ALO, Cavalcanti AL. Análise da produção científica em Odontologia no nordeste brasileiro com base em um congresso odontológico. Arq Odontol.2011;47(3):127-34.

17.Aquino SN, Martelli DR, Bonan PRF, Laranjeira AL, Martelli Júnior $H$. Produção científica odontológica e relação com agências de financiamento de pesquisa. Arq Odontol. 2009; 45(3):142-46.

18.Pontes KT, Silva EL, Macedo Filho RA, Silva DR, Lima FJ. Estudo bilbiométrico da produção científica em endodontia. Arch Health Invest. 2017;6(9):435-38.

19.Soares DM, Maciel MMSA, Figueiredo-Filho A, Melo JGA. Brazilian scientific production in periodontics: a national panorama from a bibliometric study. Rev Clin Periodoncia Implantol Rehabil Oral. 2019;12(2):66-9.

20.Taumaturgo VM, Vasques EFL, Figueiredo VMG. A Importância Da Odontologia Nas Pesquisas Em Células-Tronco. Rev Bahiana Odontol. 2016;7(2):166-71.

21.Primo BT, Grazziotin-Soares R, Bertuzzi D, Claudy MP, Hernandez PAG, Fontanella VRC. Produção científica da ULBRA: análise do número $\mathrm{e}$ do delineamento das pesquisas publicadas nos suplementos da Brazilian Oral Research (SBPqO). Stomatos. 2010;16(31):69-76.

22.Zorzanelli RT, Speroni AV, Menezes RA, Leibing A. Pesquisa com células-tronco no Brasil: a produção de um novo campo científico. Hist ciênc saúde-Manguinhos 2017;24(1):129-44.

23.Lan X, Sun Z, Chu C, Boltze J, Li S. Dental Pulp Stem Cells: An Attractive Alternative for Cell Therapy in Ischemic Stroke. Front Neurol. 2019; 10:824.

24.Aydin S, Sahin F. Stem cells derived from dental tissues. Adv Exp Med Biol. 2019;1144:123-32. 
http://dx.doi.org/10.21270/archi.v8i12.4790

\section{CONFLITO DE INTERESSES}

Os autores declaram não haver conflitos de interesse.

\section{AUTOR PARA CORRESPONDENCIA}

\section{Diego Moura Soares}

diegomsoares@hotmail.com

Submetido em 29/08/2019

Aceito em 04/12/2019 